LUNG CANCER

\title{
Significance of non-calcified pulmonary nodules in patients with extrapulmonary cancers
}

\author{
S Khokhar, A Vickers, M S Moore, S Mironov, D E Stover, M B Feinstein
}

See end of article for authors' affiliations

.....................

Correspondence to: Dr M B Feinstein, Pulmonary Division, Memorial Sloan-Kettering Cancer Center, 1275 York Avenue, New York, NY 10021,USA; feinstem@ mskcc.org

Received 15 August 2005 Accepted 19 January 2006 Published Online First 7 February 2006
Background: This study sought to determine the rate and patterns of malignancy in patients with extrapulmonary cancers and non-calcified pulmonary nodules, and to develop a statistical model to guide clinicians regarding choice of patients for diagnostic biopsy.

Method: The medical records of 151 patients evaluated at the Memorial Sloan-Kettering Cancer Center between January 1999 and December 2001 for non-calcified pulmonary nodules were reviewed. Nodules were considered malignant based on the results of a diagnostic biopsy, and were considered benign if their appearance remained stable 2 years after the initial study, if they resolved, or if a biopsy showed a non-malignant condition.

Results: Sixty four of 151 patients (42\%) were diagnosed with malignant nodules; 32 had newly diagnosed lung cancers, 28 had metastatic spread of their primary cancers, and four had lesions that were either new cancers or of undetermined aetiology. On univariate analysis the likelihood of malignancy increased with nodule size, tobacco exposure, and the finding of a solitary nodule. On multivariable analysis only nodule size and tobacco exposure were predictive of malignancy. The model had good predictive accuracy (area under the curve 0.751 ) but had insufficient discrimination for use as a clinical tool to determine which patients should undergo diagnostic biopsy.

Conclusion: Nearly half the non-calcified pulmonary nodules identified in this series were malignant. Lung cancer was more common than metastatic disease. These findings support the need for close interval follow up and a low threshold for diagnostic biopsy in patients with extrapulmonary cancers and non-calcified pulmonary nodules. In smokers, such lesions should raise concern for lung cancer.
C omputed tomographic (CT) scanning has become an integral tool for the pulmonary and oncology physician; treatment response, and monitor for disease recurrence. The increasingly widespread use of CT scans has unfortunately been complicated by the frequent finding of non-specific abnormalities such as the non-calcified pulmonary nodule (NCPN). In the Early Lung Cancer Action Project (ELCAP), a program designed to screen for lung cancer among former smokers, $23 \%$ of baseline CT scans had at least one NCPN. ${ }^{1}$ In a similar high risk population studied at the Mayo Clinic, NCPNs were detected in $51 \%$ of screened patients on their initial study. ${ }^{2}$ It has been suggested that the lower prevalence of nodules in the former study may be secondary to its use of thicker $10 \mathrm{~mm}$ sections and film (not workstation) viewing. ${ }^{3}$ There is therefore reason to believe that, as technological improvement allows ever more sensitive imaging, pulmonary nodules will only endure as a significant clinical entity.

The finding of nodules in patients already diagnosed with cancer poses a clinical dilemma. Such nodules may represent scarring, metastatic disease, or new previously unknown primary tumours, and there exist no universally accepted guidelines regarding their workup. Many nodules are too small or are found in locations that render bronchoscopy or fine needle aspiration (FNA) insufficiently sensitive to alter management. Clinicians are commonly challenged to balance the benefits of an earlier diagnosis with the potential risks of sending otherwise well patients for unnecessary biopsy. Investigators of lung cancer screening trials have thus far avoided the temptation to perform excessive numbers of biopsies on patients with benign disease. ${ }^{15}$ However, can the same be said for patients already diagnosed with cancer? What is the most appropriate way to manage such patients?
This study sought to investigate the clinical relevance of NCPNs in patients already diagnosed with solid tumours other than lung cancer. Its objective was to determine the spectrum of malignant tumours in such patients, including tumours metastatic and primary to the lung. This study also sought to determine the characteristics associated with malignancy and to develop a statistical model to guide the clinician as to choice of patients for diagnostic biopsy.

\section{METHODS \\ Subjects}

We retrospectively reviewed the electronic medical records of patients with a history of prior malignancy and at least one pulmonary nodule referred to the Pulmonary Medicine or Thoracic Surgery Services at the Memorial Sloan-Kettering Cancer Center between January 1999 and December 2001. After obtaining approval from the institutional privacy board, patients were identified by hospital discharge coding and billing records. Patients already known to have pulmonary malignancies (including primary lung cancer and metastatic disease to the lungs or mediastinum) were excluded. Patients with haematological malignancies such as leukaemia and lymphoma as well as those with non-melanoma skin cancers were also excluded.

The patients were distributed into four groups based on the previously reported likelihood that their associated primary malignancies metastasise to the lung. ${ }^{67}$ Patients in group 1 were thought to have the lowest risk of developing metastatic disease, and those in group 4 were thought to have the highest.

Abbreviations: $\mathrm{CT}$, computed tomographic scanning; ELCAP, Early Lung Cancer Action Project; FNA, fine needle aspiration; NCPN, noncalcified pulmonary nodule; PET, positron emission tomographic scanning; VATS, video assisted thoracoscopic surgery 
This method of grouping has been used previously and allows a better analysis for rare tumour types encountered by small numbers of patients. ${ }^{7}$ Group l included patients with carcinomas of the head and neck; group 2 included patients with carcinomas of the bladder, breast, cervix, oesophagus, ovary, and prostate; group 3 included patients with carcinomas of the colon, rectum, liver, adrenal, kidney, and uterus, as well as carcinoid; and group 4 included patients with thymoma, melanoma, sarcoma, and testicular cancer.

A pulmonary nodule was defined as a single radiologically distinct non-calcified lesion surrounded on all sides by pulmonary parenchyma. No size restrictions for pulmonary nodules were imposed. Although nodules above $3 \mathrm{~cm}$ in diameter may more appropriately be defined as masses, they are also referred to as nodules for purposes of simplicity. This practice has been used previously. ${ }^{1}$

\section{Data collection}

Once eligibility was established, data were retrospectively abstracted from the medical records. The following were collected:

- Name and medical record number.

- Age and sex.

- Date of initial consultation visit.

- Smoking history including the number of pack years, whether the patient was a current smoker, and time since smoking cessation, if applicable. Any use of other tobacco products such as pipes, cigars, and chewing tobacco was also noted.

- Primary cancer type(s), date of diagnosis of the primary cancer(s), staging, and all subsequent treatment (chemotherapy, radiation, or surgery).

- Clinical information regarding the nodule(s) including date of identification on CT, number of nodules present, and maximum diameter. If multiple nodules were present, only the size of the largest was included in the multivariable model. Radiographic data were acquired entirely from the official report of each CT scan. Occasionally these reports were unclear regarding one or more study variables such as whether the same nodule was being measured on all follow up examinations. In such circumstances, actual CT images were reviewed separately by two of the investigators, one of whom (SM) is a radiologist. Scans were assumed to be obtained as per routine clinical care.

- Dates and results of subsequent CT studies.

- Nodule biopsy information, if applicable, including the date, method, and all histological findings. Whether or not a nodule was metastatic or a new primary tumour was determined by the opinion of each patient's physician as documented in the medical record.

- Elapsed time between the date of diagnosis of the primary cancer and the identification of the pulmonary nodule. For cases in which the interval between the primary cancer diagnosis and the detection of the lung nodule was very short (less than 3 months), it was assumed that both conditions occurred simultaneously and that any delay was simply the consequence of the order in which tests were obtained. If a patient had more than one primary cancer, the diagnosis date of the most recent primary malignancy was used.

\section{End points}

Nodules were considered benign if there was no significant radiographic change 2 years from the initial study, if they resolved, or if a biopsy established the diagnosis of a nonmalignant condition. Nodules were considered malignant

\begin{tabular}{ll}
\hline Table 1 Characteristics of study population \\
\hline \multicolumn{2}{|l|}{ Characteristic } \\
\hline Number of patients \\
Female sex (\%) \\
Age (years) & 151 \\
Nodule size (mm) & $97(64 \%)$ \\
Stage of primary tumour (\%) & $62(54-72)$ \\
I & $12(6-20)$ \\
II & $56(37 \%)$ \\
III & $35(23 \%)$ \\
IV & $15(10 \%)$ \\
Staging data not available & $25(17 \%)$ \\
Ever smoker (\%) & $20(13 \%)$ \\
Former smoker & $101(67 \%)$ \\
Current smoker & $88(58 \%)$ \\
Other tobacco products* & $10(7 \%)$ \\
Pack years & $3(2 \%)$ \\
\hline \multicolumn{2}{|c|}{ Values are given as either frequency (\%) or median } \\
(interquartile range). & $27(13-56)$ \\
*Two patients smoked cigars, one smoked a pipe. \\
\hline
\end{tabular}

based on characteristic biopsy results. Biopsy procedures typically included fiberoptic bronchoscopy, percutaneous transthoracic fine needle aspiration (FNA), surgical biopsy via video assisted thoracoscopy (VATS), or thoracotomy.

\section{Exclusion criteria}

Patients were excluded if they had died or if they did not maintain sufficient follow up until either 2 years had passed or until a diagnostic biopsy had been performed. Patients with abnormalities described as "ground glass" in character were not included. As all radiographic data were acquired via CT scans, patients were also excluded if they did not have CT scans performed at the start and end of the study period.

Table 2 Primary malignancies found in the study population

\begin{tabular}{|c|c|c|}
\hline $\begin{array}{l}\text { Primary } \\
\text { malignancy }\end{array}$ & $\begin{array}{l}\text { No of } \\
\text { patients }\end{array}$ & $\begin{array}{l}\text { No of ever smokers } \\
\text { (\% by malignancy } \\
\text { type) }\end{array}$ \\
\hline \multicolumn{3}{|l|}{ Group 1} \\
\hline Head/neck & 11 & $9(82)$ \\
\hline \multicolumn{3}{|l|}{ Group 2} \\
\hline Bladder & 12 & $9(75)$ \\
\hline Breast & 64 & $41(64)$ \\
\hline Cervix & 1 & $0(0)$ \\
\hline Oesophagus & 2 & $1(50)$ \\
\hline Ovary & 2 & $1(50)$ \\
\hline Prostate & $1 \overline{5}$ & $11(73)$ \\
\hline Subtotal & 96 & $63(67)$ \\
\hline \multicolumn{3}{|l|}{ Group 3} \\
\hline Colon & 15 & $10(67)$ \\
\hline Rectum & 4 & $2(50)$ \\
\hline Liver & 1 & $1(100)$ \\
\hline Carcinoid & 1 & $1(100)$ \\
\hline Adrenal & 1 & $0(0)$ \\
\hline Kidney & 6 & 1 (17) \\
\hline Uterus & 6 & $3(50)$ \\
\hline Subtotal & 34 & $18(53)$ \\
\hline \multicolumn{3}{|l|}{ Group 4} \\
\hline Thymus & 1 & $0(0)$ \\
\hline Melanoma & 8 & $6(75)$ \\
\hline Sarcoma* & 7 & $5(71)$ \\
\hline Testes & 4 & $3(75)$ \\
\hline Kaposi's sarcoma & 2 & $2(100)$ \\
\hline Subtotal & 22 & $16(73)$ \\
\hline Totalt & 151 & $101(67)$ \\
\hline \multicolumn{3}{|c|}{$\begin{array}{l}\text { *Includes one case each of benign metastasising leiomyosarcoma, } \\
\text { osteogenic sarcoma, uterine sarcoma, synovial cell sarcoma, and } \\
\text { chondrosarcoma, as well as two cases of unspecified sarcomas. } \\
\text { †All tumour types were analysed individually. Because some patients had } \\
\text { more than one primary tumour, the sum of all figures in a given column } \\
\text { may exceed that reported as the total. }\end{array}$} \\
\hline
\end{tabular}


Table 3 Nodule outcomes based on primary malignancy

\begin{tabular}{|c|c|c|c|c|c|c|}
\hline \multirow[b]{2}{*}{ Primary malignancy } & \multirow[b]{2}{*}{$\begin{array}{l}\text { Total no } \\
\text { of patients }\end{array}$} & \multirow[b]{2}{*}{$\begin{array}{l}\text { No }(\%) \text { of patients } \\
\text { with malignant } \\
\text { nodules }\end{array}$} & \multicolumn{4}{|c|}{ Type of malignant nodule } \\
\hline & & & $\begin{array}{l}\text { No }(\%) \text { of patients } \\
\text { with metastatic } \\
\text { nodules }\end{array}$ & $\begin{array}{l}\text { No }(\%) \text { of patients } \\
\text { with lung cancers }\end{array}$ & $\begin{array}{l}\text { No }(\%) \text { of patients } \\
\text { with second primary } \\
\text { cancers }\end{array}$ & $\begin{array}{l}\text { No }(\%) \text { of patients } \\
\text { where primary site } \\
\text { undetermined }\end{array}$ \\
\hline \multicolumn{7}{|l|}{ Group 1} \\
\hline Head/neck & 11 & $9(82 \%)$ & 2 (22\%) & $6(67 \%)$ & $0(0 \%)$ & $1(11 \%)$ \\
\hline \multicolumn{7}{|l|}{ Group 2} \\
\hline Bladder & 12 & $4(33 \%)$ & $0(0 \%)$ & $4(100 \%)$ & $0(0 \%)$ & $0(0 \%)$ \\
\hline Breast & 64 & $16(25 \%)$ & $10(63 \%)$ & $5(31 \%)$ & $1(6 \%)$ & $0(0 \%)$ \\
\hline Cervix & 1 & 1 (100\%) & 1 (100\%) & $0(0 \%)$ & $0(0 \%)$ & $0(0 \%)$ \\
\hline Oesophagus & 2 & $1(50 \%)$ & $0(0 \%)$ & $0(0 \%)$ & $0(0 \%)$ & $1(100 \%)$ \\
\hline Ovary & 2 & $1(50 \%)$ & $0(0 \%)$ & $1(100 \%)$ & $0(0 \%)$ & $0(0 \%)$ \\
\hline Prostate & 15 & $8(53 \%)$ & $1(13 \%)$ & 7 (89\%) & $0(0 \%)$ & $0(0 \%)$ \\
\hline Subtotal & 96 & $31(32 \%)$ & $12(39 \%)$ & $17(55 \%)$ & $1(3 \%)$ & $1(3 \%)$ \\
\hline \multicolumn{7}{|l|}{ Group 3} \\
\hline Colon & 15 & $8(53 \%)$ & $3(38 \%)$ & $5(62 \%)$ & $0(0 \%)$ & $0(0 \%)$ \\
\hline Rectum & 4 & $3(75 \%)$ & $3(100 \%)$ & $0(0 \%)$ & $0(0 \%)$ & $0(0 \%)$ \\
\hline Liver & 1 & $1(100 \%)$ & $0(0 \%)$ & $1(100 \%)$ & $0(0 \%)$ & $0(0 \%)$ \\
\hline Carcinoid & 1 & 1 (100\%) & $0(0 \%)$ & $1(100 \%)$ & $0(0 \%)$ & $0(0 \%)$ \\
\hline Adrenal & 1 & $1(100 \%)$ & $1(100 \%)$ & $0(0 \%)$ & $0(0 \%)$ & $0(0 \%)$ \\
\hline Kidney & 6 & $2(33 \%)$ & $2(100 \%)$ & $0(0 \%)$ & $0(0 \%)$ & $0(0 \%)$ \\
\hline Uterus & 6 & $2(33 \%)$ & $1(50 \%)$ & $1(50 \%)$ & $0(0 \%)$ & $0(0 \%)$ \\
\hline Subtotal & 34 & $18(53 \%)$ & $10(56 \%)$ & $8(44 \%)$ & $0(0 \%)$ & $0(0 \%)$ \\
\hline \multicolumn{7}{|l|}{ Group 4} \\
\hline Thymus & 1 & $1(100 \%)$ & $1(100 \%)$ & $0(0 \%)$ & $0(0 \%)$ & $0(0 \%)$ \\
\hline Melanoma & 8 & $4(50 \%)$ & $1(25 \%)$ & $2(50 \%)$ & $1(25 \%)$ & $0(0 \%)$ \\
\hline Sarcoma* & 7 & $2(33 \%)$ & $2(67 \%)$ & 1 (33\%) & $0(0 \%)$ & $0(0 \%)$ \\
\hline Testes & 4 & $1(25 \%)$ & $1(100 \%)$ & $0(0 \%)$ & $0(0 \%)$ & $0(0 \%)$ \\
\hline Kaposi's sarcoma & 2 & $1(50 \%)$ & $0(0 \%)$ & $1(100 \%)$ & $0(0 \%)$ & $0(0 \%)$ \\
\hline Subtotal & 22 & $9(41 \%)$ & $5(50 \%)$ & $4(40 \%)$ & $1(10 \%)$ & $0(0 \%)$ \\
\hline Total $^{*} \dagger$ & 151 & $64(42 \%)$ & $28(44 \%)$ & $32(50 \%)$ & $2(3 \%)$ & $2(3 \%)$ \\
\hline
\end{tabular}

*One patient with chondrosarcoma had both metastatic disease and primary lung cancer and was included in both categories.

†All tumour types were analysed individually. Because some patients had more than one primary tumour, the sum of all figures in a given column may exceed that reported as the total.

\section{Statistical analysis}

A multivariable logistic regression model was developed to predict the binary end point of whether or not malignancy (either a metastatic lesion or a lung primary) would be found on biopsy. Included in this model were age; pack years; stage of primary cancer (categorised as stage 3 or 4: yes/no); number of months elapsed from diagnosis; number of nodules (multifocal/single); patient on active cancer treatment (yes/no); and nodule size. A binary variable was included as to whether the primary tumour is likely to metastasise to the lungs. Patients in groups 1 and 2 were coded 0 and those in groups 3 and 4 were coded 1 . Nine patients were recorded as smokers but there was no quantification of smoking history in the medical record. These patients were not included in summary statistics; for the multivariable model, pack years were imputed using linear regression from age. Staging information was not available for 17 patients and three patients had tumours, such as Kaposi's sarcoma, for which no TNM staging system exists. Such patients were categorised as high stage. Sensitivity analyses were conducted using alternative approaches such as defining these 20 patients as low stage or using a separate "stage missing" category without important differences in any results.

Before analysis it was anticipated that nodule size and pack years of smoking might not have a linear relationship with malignancy. We therefore created restricted cubic splines for these two variables with knots at the tertiles. We pre-specified that the initial model would not include the splines due to limited degrees of freedom. We also prespecified a threshold of $15 \%$ risk of malignancy predicted from the model as the cut off for determining which patients would be recommended for biopsy. All analyses were conducted using Stata Version 8.2 (Stata Corp, College Station, TX, USA).

\section{RESULTS}

\section{Study population}

We identified 151 patients who underwent evaluation for pulmonary nodules. Demographic data and staging of the primary malignancies are shown in table 1 . The majority of the patients were women and most were ever smokers. Ten patients who had two extrapulmonary cancers and one patient who had three were entered into the database more than once. Thus, 151 patients had a cumulative history of 163 extrapulmonary cancers. We considered their stage to be the highest stage of all tumours encountered. The median time interval between the diagnosis of the primary tumour and the pulmonary nodule(s) was 33 months (interquartile range 8$80)$. Twenty nine patients were referred within 3 months of diagnosis of their primary cancer.

Of 151 patients evaluated for non-specific pulmonary nodules, $74(49 \%)$ were referred upon initial evaluation to serial imaging and 77 (51\%) were referred for immediate biopsy or resection. Thirty seven patients, half of the 74 patients sent for serial imaging, eventually demonstrated nodule changes that mandated biopsy. Thus, 114 of the 151 patients $(75 \%)$ underwent biopsy at some point during their clinical course. Types of biopsy included surgical wedge resection $(n=62)$, FNA $(n=24)$, fibreoptic bronchoscopy $(n=18)$, lobectomy $(n=7)$, thoracentesis $(n=1)$, mediastinoscopy $(\mathrm{n}=1)$, and pneumonectomy $(\mathrm{n}=1)$. Histological data were available for all patients biopsied.

Table 2 shows the types of primary malignancies found in the study population and the prevalence of smoking within each diagnosis. Breast cancer was the most prevalent cancer type. Smoking rates were similar among the major cancer groups.

\section{Malignant nodules}

Table 3 summarises the prevalence of patients with malignant nodules in this cohort. All data are expressed in terms of 
Table 4 Nodule outcomes of patients with solitary and multiple pulmonary nodules

\begin{tabular}{|c|c|c|c|c|c|c|}
\hline \multirow[b]{2}{*}{$\begin{array}{l}\text { Type of } \\
\text { nodule }\end{array}$} & \multirow[b]{2}{*}{$\begin{array}{l}\text { Total no } \\
\text { of patients }\end{array}$} & \multirow[b]{2}{*}{$\begin{array}{l}\text { No }(\%) \text { of patients } \\
\text { with malignant } \\
\text { nodules }\end{array}$} & \multicolumn{4}{|c|}{ Type of malignant nodules } \\
\hline & & & $\begin{array}{l}\text { No }(\%) \text { of patients } \\
\text { with metastatic } \\
\text { nodules }\end{array}$ & $\begin{array}{l}\text { No }(\%) \text { of patients } \\
\text { with lung cancers }\end{array}$ & $\begin{array}{l}\text { No }(\%) \text { of patients } \\
\text { with second primary } \\
\text { cancers }\end{array}$ & $\begin{array}{l}\text { No }(\%) \text { of patients } \\
\text { where primary site } \\
\text { undetermined }\end{array}$ \\
\hline Solitary & 59 & $31(53 \%)$ & $9(29 \%)$ & $19(61 \%)$ & $1(3 \%)$ & $2(7 \%)$ \\
\hline Multiple* & 92 & $33(36 \%)$ & $19(57 \%)$ & $13(39 \%)$ & $1(3 \%)$ & $1(3 \%)$ \\
\hline Total & 151 & $64(42 \%)$ & $28(43 \%)$ & $32(49 \%)$ & $2(3 \%)$ & $3(5 \%)$ \\
\hline
\end{tabular}

patient number. Of 151 patients studied, 65 malignant lung nodules were detected in 64 patients. Among these, 28 patients had nodules resulting from the metastatic spread of extrapulmonary malignancies. Thirty two patients had newly diagnosed lung cancers. Two patients developed malignancies that were neither their previously known primary neoplasm nor a new lung cancer (carcinoid in one patient and non-Hodgkin's lymphoma in the other). No reference existed in the medical record for two patients to specify whether their malignant lung nodules represented metastases or second primary tumours. The biopsy of one patient revealed both a new lung primary as well as metastatic chondrosarcoma. This patient was listed in both categories (primary lung cancer and metastatic disease).

Patients in group 1 (with head/neck cancer) had the highest percentage of malignant nodules. The ratio of second primary lung cancer to metastatic disease in this group was 6:2. Patients in group 4 (with thymoma, melanoma, sarcoma, renal, or testicular cancer) had nearly equal numbers of patients with primary lung cancer and metastatic disease (ratio 4:5).

Pulmonary nodules were described as solitary in 59 patients and multiple in 92 patients (table 4). Thirty one patients $(53 \%)$ with solitary nodules had malignant lesions, of whom the majority $(\mathrm{n}=19,61 \%)$ had new lung cancers. In contrast, patients with multiple nodules had malignant lesions less commonly and, when malignancy was present, were more likely to have metastatic disease. Thirty three $(36 \%)$ of the 92 patients presenting with multiple lung lesions had malignant nodules of whom 13 (39\%) had lung cancer and 19 (57\%) had metastatic disease.

In univariate analysis we found statistically significant associations between cancer and pack years of smoking $(p<0.0005)$, nodule size $(p<0.0005)$, the propensity of the primary tumour to metastasise to the lungs $(p=0.018)$, and the finding of a single nodule $(p=0.044)$. Age $(p=0.12)$, stage of the primary cancer $(p=0.062)$, active cancer therapy $(p=0.7)$, and elapsed time from diagnosis $(p=0.7)$ were not statistically significant predictors. However, the negative predictive value did not exceed $85 \%$ for any univariate predictor.

The results of the initial multivariable model are shown in table 5. Only pack years and nodule size were statistically significant predictors of nodule malignancy. Although the area under the curve (AUC) was relatively good $(0.751)$, the model is unlikely to have clinical value: only eight patients had predicted probability of malignancy below the prespecified threshold of $15 \%$, and one of these was a false negative.

As an exploratory analysis, we removed non-predictive variables and used restricted cubic splines, with knots at the tertiles, to allow nodule size and pack years to have a nonlinear relationship to malignancy. Model fit was slightly improved (AUC 0.768) and, more importantly, a clinically relevant number of patients fell below the $15 \%$ threshold for avoiding biopsy (table 6). However, there were four false negatives in the 30 patients who would have been recommended to avoid biopsy. The negative predictive value $(87 \%)$ is not importantly higher than the cut off ( $85 \%$ probability of no cancer) and so, by decision theory, use of the model will not lead to better clinical decisions than a strategy of performing biopsies in all patients. ${ }^{8}$

\section{DISCUSSION}

This study demonstrated a substantial (42\%) overall rate of malignancy in patients with extrapulmonary cancers found to have NCPNs. The prevalence of lung cancer was higher than metastatic disease. Although tobacco exposure (expressed in pack years), nodule size, propensity of the primary tumour to metastasise to the lungs, and the finding of a single nodule were related to the rate of malignancy on univariate analysis, only tobacco exposure and nodule size were significant using a multivariable model.

The multivariable model was designed to predict which patients should undergo diagnostic biopsy. Although relatively accurate for studies of this type (AUC 0.768), it is probably not of important clinical usefulness. Given the assumption that any patient whose risk of malignancy exceeds $15 \%$ would be referred for biopsy, four of the 30 patients advised to avoid biopsy by this model would have had cancer. Nevertheless, these data collectively encourage a relatively low threshold for tissue sampling, particularly among patients with large nodules or any history of tobacco use.

The lungs are known to be a common destination for cancer cells originating at other sites. Some necropsy studies

\begin{tabular}{llll} 
Table 5 & Multivariable logistic model predicting malignancy & \\
\hline Variable & Odds ratio & $95 \% \mathrm{Cl}$ & p value \\
\hline Age (per 10 years) & 1.06 & 0.77 to 1.45 & 0.7 \\
Pack years & 1.21 & 1.05 to 1.38 & 0.007 \\
Primary stage 3 or 4 & 1.57 & 0.74 to 3.33 & 0.2 \\
Size of nodule (cm) & 1.07 & 1.03 to 1.12 & 0.001 \\
Primary metastasises to lungs & 0.77 & 0.33 to 1.79 & 0.5 \\
Months elapsed from diagnosis of primary & 1.00 & 0.99 to 1.01 & 0.8 \\
Patient on active treatment & 1.52 & 0.66 to 3.51 & 0.3 \\
Multifocal nodules & 0.82 & 0.36 to 1.86 & 0.6 \\
\hline
\end{tabular}


Table 6 Two by two table for decision as to whether patient should have a biopsy sample taken

\begin{tabular}{|c|c|c|c|}
\hline & Cancer & No cancer & Total \\
\hline Recommend biopsy & 60 & 61 & 121 \\
\hline Recommend avoiding biopsy & 4 & 26 & 30 \\
\hline Total & 64 & 87 & 151 \\
\hline
\end{tabular}

Patients with a risk of malignancy of $15 \%$ or more were categorised as "recommend biopsy".

have reported evidence of pulmonary metastases to be present in 50\% or more of patients with sarcoma, melanoma, as well as cancer of the breast, prostate, thyroid, uterus, and kidney. ${ }^{10}$ Our study also found a substantial rate of metastatic disease, although it is notable how frequently lung cancer was found; among smokers, the rate of newly diagnosed lung cancer exceeded that of metastatic disease. It also accounted for nearly half of all thoracic malignancies among patients with multiple nodules and with such tumours as melanoma, sarcoma, and testicular cancer. Therefore, caution of lung cancer should remain, even among these patients who have traditionally been thought to be at highest risk for metastatic disease.

This study is not the first to examine the causes of pulmonary nodules in patients with cancer. In 1978, before the widespread use of CT scanning, Cahan et al ${ }^{6}$ reviewed thoracotomy results obtained over 35 years from 800 patients with cancer. In approximately 500 cases the nodules were non-small cell lung cancer, while in 196 cases they represented metastatic disease. Patients with head and neck cancers, bladder, breast, and prostate cancers were more likely to have a lung cancer, and patients with melanoma, bone cancers, soft tissue sarcomas, and testicular cancers were more likely to have metastatic disease. At about the same time, Neifeld $e t$ al ${ }^{11}$ reviewed 182 thoracotomies performed in 152 patients with extrathoracic malignancies and pulmonary nodules; $80 \%$ of patients had malignant lesions. The majority (86\%) had metastatic lesions in the setting of a relatively high percentage of patients with sarcoma and melanoma. Casey et $a l^{12}$ found a higher prevalence of primary lung cancer than metastatic disease in 42 patients with breast cancer who underwent lung biopsy, $83 \%$ of whom were smokers. These older studies are limited by the fact that nodules were detected and analysed by conventional chest radiography or first generation CT scanners; the high malignancy rates they report may be related to the fact that only the largest and most suspicious nodules were seen.

More recently, Quint et al $^{7}$ reported on 149 patients with a known history of extrapulmonary malignancy and at least one solitary NCPN $5.0 \mathrm{~mm}$ or more in diameter found on the chest CT scan. They also concluded that patients with a history of head and neck cancer were much more likely to have new primary lung cancer than metastatic disease. Mery et $a l^{13}$ analysed 1104 patients with or without a cancer diagnosis who underwent excisional biopsy of a pulmonary nodule. The rate of malignancy in patients with an antecedent non-pulmonary cancer diagnosis was $79 \%$. Approximately half of these patients were diagnosed with lung cancer. The authors concluded that age, cigarette smoking, and an antecedent history of cancer $\geqslant 5$ years previously were predictors of malignancy.

Our study differs from these earlier reports in several respects. Most used univariate analyses only and therefore could not exclude potential relationships between some variables such as age and pack years which they independently associated with the risk of malignancy. ${ }^{7}$ Mery et al developed a multivariable model to predict prospectively whether malignant nodules represent metastases or secondary lung cancers. However, their model did not predict the more clinically relevant end point-namely, whether a nodule is sufficiently likely to be malignant and thereby require biopsy. Furthermore, our study includes patients undergoing serial imaging and is not limited to biopsy data, which suggests that it may more accurately represent the variety of patients seen in a typical outpatient pulmonary or oncology practice. Serial imaging has become a commonly employed alternative technique to biopsy in the evaluation of non-specific pulmonary nodules, especially when the probability of cancer is low. Serial imaging has been used extensively in ELCAP and other recent studies. ${ }^{14-16}$ We felt it necessary to include patients managed with serial imaging in our analysis; their use may explain our lower overall rate of malignancy $(42 \%)$ compared with earlier reports.

Our study has some limitations. As it was retrospective, radiographs were not performed in a standardised fashion. Whenever thick collimated scans were obtained, it is possible that some pulmonary nodules-which otherwise would have justified referral-may have remained undetected. If most of these undetected nodules were benign, we may have overestimated the "true" rate of malignancy in patients with pulmonary nodules. Although relying on physician notes to determine whether malignancies were primary or metastatic could bias some results, we felt this strategy to be the most reliable means given the limits of the study design. While some tumours such as melanoma are readily identifiable pathologically as metastases within the lung, others are not. A lesion of squamous cell carcinoma in the lung of a patient with prior head/neck cancer would look identical, regardless of the primary tumour site. As most such patients had unfortunately died by the time of data collection, we felt the most reliable way to handle this dilemma was to rely on the medical professionals who knew them best. The prevalence of smokers in this study exceeded the national average in the US, so we may have encountered a higher rate of lung cancer than otherwise would be expected. Alternatively, the high rate of lung cancer may, at least in part, have been affected by observation bias. Oncologists, for instance, may be less likely to refer patients for evaluation whose radiographic abnormalities already strongly indicate metastatic disease. Finally, we did not include nodule morphology such as the presence or absence of spiculation in the multivariable analysis. While certain morphologies have been associated with the risk of lung cancer, we have found it difficult to quantify them among smaller nodules. As technology improves, it is expected that morphology will be explored further.

Taken together, these findings support the need for close interval follow up and a low threshold for biopsy in patients with extrapulmonary malignancies and NCPNs. In smokers the finding of such lesions should also raise concern for lung cancer. Lung cancer is not excluded by the finding of multiple nodules or neoplasms which are traditionally thought to metastasise, such as melanoma, sarcoma, and testicular cancer.

\section{Authors' affiliations}

S Khokhar, M S Moore, D E Stover, M B Feinstein, Division of Pulmonary Medicine, Memorial Sloan-Kettering Cancer Center, New York, USA

S Mironov, Division of Radiology, Memorial Sloan-Kettering Cancer Center, New York, USA

A Vickers, Division of Epidemiology and Biostatistics, Memorial SloanKettering Cancer Center, New York, USA

The studies described in this manuscript were supported by internal funding only and not by external sources, with the exception of $\mathrm{Dr}$ Vickers whose contribution was funded by a P50-CA92629 SPORE from the National Cancer Institute.

Competing interests: None of the authors has any competing interest to the material covered by this manuscript. 
Dr Feinstein is the sponsor of this study and supervised all steps of this research project. He developed the hypothesis and study design in consultation with the other authors and is responsible for assessing data quality and disseminating these results through publications and national meetings.

Ethics approval: This study was approved by the institutional privacy board of the Memorial Sloan-Kettering Cancer Center in New York City. This board is designed to oversee retrospective studies, such as this one, to ensure that they maintain compliance with institutional and governmental guidelines of medical ethics and patient confidentiality. Given the study design, no informed consent was required.

\section{REFERENCES}

1 Henschke Cl, McCauley DI, Yankelevitz DF, et al. Early Lung Cancer Action Project: overall design and findings from baseline screening. Lancet 1999;354:99-105.

2 Swensen SJ, Jett JR, Hartman TE, et al. CT screening for lung cancer: five-year prospective experience. Radiology 2005;235:259-65.

3 Swensen SJ, Jett JR, Sloan JA, et al. Screening for lung cancer with low-dose spiral computed tomography. Am J Respir Crit Care Med 2002; 165:508-13.

4 Tillich M, Kammerhuber F, Reittner P, et al. Detection of pulmonary nodules with helical CT: comparison of cine and film-based viewing. AJR Am J Roentgenol 1997;169:1611-4.
5 Jett JR, Midthun DE. Screening for lung cancer: current status and future directions. Thomas A Neff lecture. Chest 2004;125(5 Suppl): 158-62S.

6 Cahan WG, Shah JP, Castro EB. Benign solitary lung lesions in patients with cancer. Ann Surg 1978;187:241-4.

7 Quint LE, Park CH, lannettoni MD. Solitary pulmonary nodules in patients with extrapulmonary neoplasms. Radiology 2000;217:257-61.

8 Hunink M, Glasziou P, Siegel J. Decision-making in health and medicine: integrating evidence and values. New York: Cambridge University Press, 2001.

9 Luce JA. Metastatic and malignant tumors. In: Murray JF, Nadel J, eds. Textbook of respiratory medicine.3rd ed. Philadelphia: WB Saunders, 2000: 1470.

10 Weiss L, Gilbert HA. Pulmonary metastasis. Boston: GK Hall, 1978.

11 Neifeld JP, Michaelis LL, Doppman JL. Suspected pulmonary metastases: correlation of chest $x$-ray, whole lung tomograms, and operative findings. Cancer 1977;39:383-7.

12 Casey JJ, Stempel BG, Scanlon EF, et al. The solitary pulmonary nodule in the patient with breast cancer. Surgery 1984;96:801-5.

13 Mery CM, Pappas AN, Bueno R, et al. Relationship between a history of antecedent cancer and the probability of malignancy for a solitary pulmonary nodule. Chest 2004;125:2175-81.

14 Cummings SR, Lillington GA, Richard RJ. Managing solitary pulmonary nodules. The choice of strategy is a "close call". Am Rev Respir Dis $1986 ; 134: 453-60$

15 Libby DM, Smith JP, Altorki NK, et al. Managing the small pulmonary nodule discovered by CT. Chest 2004; 125:1522-9.

16 Ost D, Fein AM, Feinsilver SH. Clinical practice. The solitary pulmonary nodule. N Engl J Med 2003;348:2535-42.

\section{Clinical Evidence-Call for contributors}

Clinical Evidence is a regularly updated evidence-based journal available worldwide both as a paper version and on the internet. Clinical Evidence needs to recruit a number of new contributors. Contributors are healthcare professionals or epidemiologists with experience in evidence-based medicine and the ability to write in a concise and structured way.

Areas for which we are currently seeking contributors:

- Pregnancy and childbirth

- Endocrine disorders

- Palliative care

- Tropical diseases

We are also looking for contributors for existing topics. For full details on what these topics are please visit www.clinicalevidence.com/ceweb/contribute/index.jsp

However, we are always looking for others, so do not let this list discourage you.

Being a contributor involves:

- Selecting from a validated, screened search (performed by in-house Information Specialists) epidemiologically sound studies for inclusion.

- Documenting your decisions about which studies to include on an inclusion and exclusion form, which we keep on file.

- Writing the text to a highly structured template (about 1500-3000 words), using evidence from the final studies chosen, within 8-10 weeks of receiving the literature search.

- Working with Clinical Evidence editors to ensure that the final text meets epidemiological and style standards.

- Updating the text every 12 months using any new, sound evidence that becomes available. The Clinical Evidence in-house team will conduct the searches for contributors; your task is simply to filter out high quality studies and incorporate them in the existing text.

If you would like to become a contributor for Clinical Evidence or require more information about what this involves please send your contact details and a copy of your CV, clearly stating the clinical area you are interested in, to CECommissioning@bmigroup.com.

\section{Call for peer reviewers}

Clinical Evidence also needs to recruit a number of new peer reviewers specifically with an interest in the clinical areas stated above, and also others related to general practice. Peer reviewers are healthcare professionals or epidemiologists with experience in evidence-based medicine. As a peer reviewer you would be asked for your views on the clinical relevance, validity, and accessibility of specific topics within the journal, and their usefulness to the intended audience (international generalists and healthcare professionals, possibly with limited statistical knowledge). Topics are usually 1500-3000 words in length and we would ask you to review between 2-5 topics per year. The peer review process takes place throughout the year, and out turnaround time for each review is ideally 10-14 days. If you are interested in becoming a peer reviewer for Clinical Evidence, please complete the peer review questionnaire at www. clinicalevidence.com/ceweb/contribute/peerreviewer.jsp 